\title{
ETS Transcription Factor Expression and Conversion During Prostate and Breast Cancer Progression
}

\author{
Dennis K. Watson ${ }^{1,2, *}$, David P. Turner ${ }^{1}$, Melissa N. Scheiber ${ }^{1}$, Victoria J. Findlay ${ }^{1}$ and \\ Patricia M. Watson ${ }^{3}$ \\ Departments of Pathology and Laboratory Medicine ${ }^{1}$, Biochemistry and Molecular Biology ${ }^{2}$, and Medicine ${ }^{3}$, Hollings \\ Cancer Center, Medical University of South Carolina, USA
}

\begin{abstract}
ETS factors are known to act as positive or negative regulators of the expression of genes including those that control response to various signaling cascades, cellular proliferation, differentiation, hematopoiesis, apoptosis, adhesion, migration, invasion and metastasis, tissue remodeling, ECM composition and angiogenesis. During cancer progression, altered ETS gene expression disrupts the regulated control of many of these biological processes. Although it was originally observed that specific ETS factors function either as positive or negative regulators of transcription, it is now evident that the same ETS factor may function in reciprocal fashions, reflecting promoter and cell context specificities. This report will present a discussion of ETS factor expression during prostate and breast cancer progression and its functional roles in epithelial cell phenotypes.

The ETS genes encode transcription factors that have independent activities but are likely to be part of an integrated network. While previous studies have focused on single ETS factors in the context of specific promoters, future studies should consider the functional impact of multiple ETS present within a specific cell type. The pattern of ETS expression within a single tissue is, not surprisingly, quite complex. Multiple ETS factors may be able to regulate the same genes, albeit at different magnitude or in different directions. Furthermore, the precise balance between cancer promotion and inhibition by ETS factors, which may differentially regulate specific target genes, can thus control its progression. These concepts form the basis of the hypothesis that "Ets conversion" plays a critical role during tumor progression. Examples supporting this hypothesis will be described.
\end{abstract}

Keywords: ETS, transcription, prostate cancer, breast cancer, cancer progression, biological control.

\section{ETS GENE FAMILY}

The oncogene v-ets was first characterized in 1983 as part of the transforming fusion protein of an avian retrovirus, E26 (ets, E26 transforming sequence). Subsequent identification of v-ets related genes from metazoan species established the Ets family as one of the largest families of transcriptional regulators, with diverse functions and activities (for reviews, see [1-4] and references therein). To date, 27 human ETS family members have been identified (Fig. (1) and Table 1). All Ets genes retain a conserved winged helixturn-helix DNA binding domain (the ETS domain) of $\sim 85$ amino acids that recognizes a core GGAA/T sequence (ETS binding site, EBS). ETS proteins, with the exception of GABP $\alpha$, bind DNA as monomers. The second conserved domain found in a subset of ETS genes is the pointed (PNT) domain. This $65-85$ amino acid domain is found in 11 of 27 human ETS genes and has been shown to function in protein-protein interaction and oligomerization. ETS factors have been classified into 12 subgroups based upon Ets domain sequence homology: ETS, ERG, PEA3, ETV2, TCF, GABP, ELF, SPI, TEL, ERF, PDEF and ESE $[2,5]$ (See Table 1 for subgroup members). In addition, a subset of 4 ETS family genes (ESE1, ESE2, ESE3, PDEF) has been

\footnotetext{
*Address correspondence to this author at the Hollings Cancer Center, Room H0310, Medical University of South Carolina, 86 Jonathan Lucas Street, Charleston, SC 29425, USA; Tel: 843-792-3962;

E-mail:watsondk@musc.edu
}

placed into a unique subgroup based upon their restricted expression to tissues with high epithelial cell content [6].

ETS factors are known to act as positive or negative regulators of the expression of genes including those that control response to various signaling cascades, cellular proliferation, differentiation, hematopoiesis, apoptosis, adhesion, migration, invasion and metastasis, tissue remodeling, ECM composition and angiogenesis. ETS target gene specificity is provided by sequences flanking the core GGAA/T element, and functional activity is further modulated by posttranslational modification(s) [7] and interaction with other nuclear factors $[8,9]$. Our earlier literature survey enabled identification of over 200 ETS target genes [10] and, to date, over 500 ETS target genes have been defined based upon the presence of functional EBS in their regulatory regions (Watson, unpublished). While most ETS factors were initially characterized as transcriptional activators or repressors, it has become evident that several ETS factors can function as both activators or repressors, depending upon the promoter and cellular context.

During cancer progression, ETS genes acquire point mutations, genomic amplification, loss or rearrangements [2], resulting in altered ETS gene expression which disrupts the regulated control of many complex biological processes, promoting cellular proliferation and inhibiting apoptosis, enhancing cell migration, invasiveness, and metastasis as well as angiogenesis (Fig. 2). 


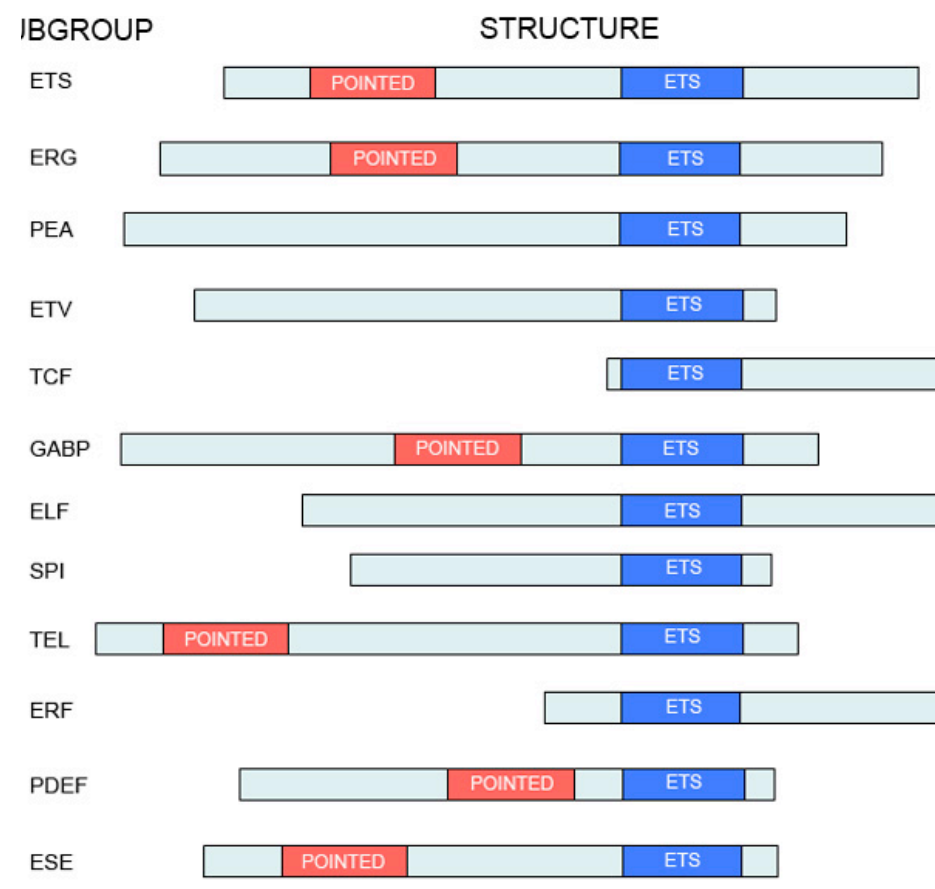

Fig. (1). The human ETS family of transcription factors. The main structural organization of each human ETS subfamily (See Table 1) is depicted. The ETS domain is indicated by the blue box. The Pointed domain is indicated by the red box.

Table 1. The Human ETS Gene Family

\begin{tabular}{|c|c|c|c|c|c|c|c|c|c|}
\hline & Subgroup & Name & Unigene Name & Alternative Names & GenBank & Locus & Size & ETS & Pointed \\
\hline 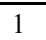 & ETS & ETS1 & ETS1 & & J04101 & $11 \mathrm{q} 23.3$ & 441 & $331-416$ & $254-135$ \\
\hline 2 & & ETS2 & ETS2 & & J04102 & $21 \mathrm{q} 22.3$ & 469 & $369-443$ & $88-168$ \\
\hline 4 & & FLI1 & FLI1 & ERGB & M98833 & $11 \mathrm{q} 24.1-\mathrm{q} 24.3$ & 452 & $277-361$ & $115-196$ \\
\hline 5 & & FEV & FEV & & Y08976 & $2 q 36$ & 238 & $43-126$ & none \\
\hline 8 & & ER81 & ETV1 & & $\mathrm{X} 87175$ & $7 \mathrm{p} 21.3$ & 458 & $314-397$ & none \\
\hline 9 & ETV & ER71 & ETV2 & ETSRP71 & NM_014209 & $19 \mathrm{q} 13.12$ & 370 & $265-350$ & none \\
\hline 10 & TCF & ELK1 & ELK1 & & M25269 & Xp11.2 & 428 & $7-92$ & none \\
\hline 11 & & SAP1 & ELK4 & & M85165 & $1 \mathrm{q} 32$ & 431 & $4-89$ & none \\
\hline 12 & & NET & ELK3 & SAP2, ERP & Z36715 & $12 q 23$ & 407 & $5-85$ & none \\
\hline 16 & & MEF & ELF4 & ELFR & U32645 & $\mathrm{Xq} 26$ & 663 & $204-290$ & none \\
\hline 17 & SPI1 & SPI1 & SPI1 & PU.1, SFPI1, SPI-A & $\mathrm{X} 52056$ & $11 \mathrm{p} 11.2$ & 264 & $168-240$ & none \\
\hline 18 & & SPIB & SPIB & & X96998 & $19 q 13.3-q 13.4$ & 262 & $169-251$ & none \\
\hline 19 & & SPIC & SPIC & & NM_152323 & $12 \mathrm{q} 23.2$ & 248 & 111-193 & none \\
\hline 20 & TEL & TEL & ETV6 & & $\mathrm{U} 11732$ & $12 \mathrm{p} 13$ & 452 & $340-419$ & $38-119$ \\
\hline 21 & & TEL2 & ETV7 & TEL-B & AF147782 & $6 \mathrm{p} 21$ & 264 & $149-228$ & $49-114$ \\
\hline 22 & ERF & ERF & ERF & & U15655 & $19 \mathrm{q} 13$ & 548 & $26-106$ & none \\
\hline 23 & & PE-1 & ETV3 & METS & L16464 & $1 q 21-q 23$ & 250 & $56-140$ & none \\
\hline 24 & PDEF & PDEF & SPDEF & & AF071538 & $6 \mathrm{p} 21.3$ & 335 & $248-332$ & $138-211$ \\
\hline 25 & ESE & ESE1 & ELF3 & ESX, JEN, ERT, EPR1 & AF110184 & $1 \mathrm{q} 32.2$ & 371 & $275-354$ & $47-132$ \\
\hline 26 & & ESE2 & ELF5 & & AF049703 & $11 \mathrm{p} 13-\mathrm{p} 12$ & 255 & $165-243$ & $46-115$ \\
\hline
\end{tabular}

List of the known human ETS genes, including gene names and alternative nomenclature, GenBank accession number, chromosomal location, size of protein (amino acids), approximate boundaries of the Ets domain ( 85 amino acids) and approximate boundaries of the Pointed domain (65-85 amino acids, if present). 


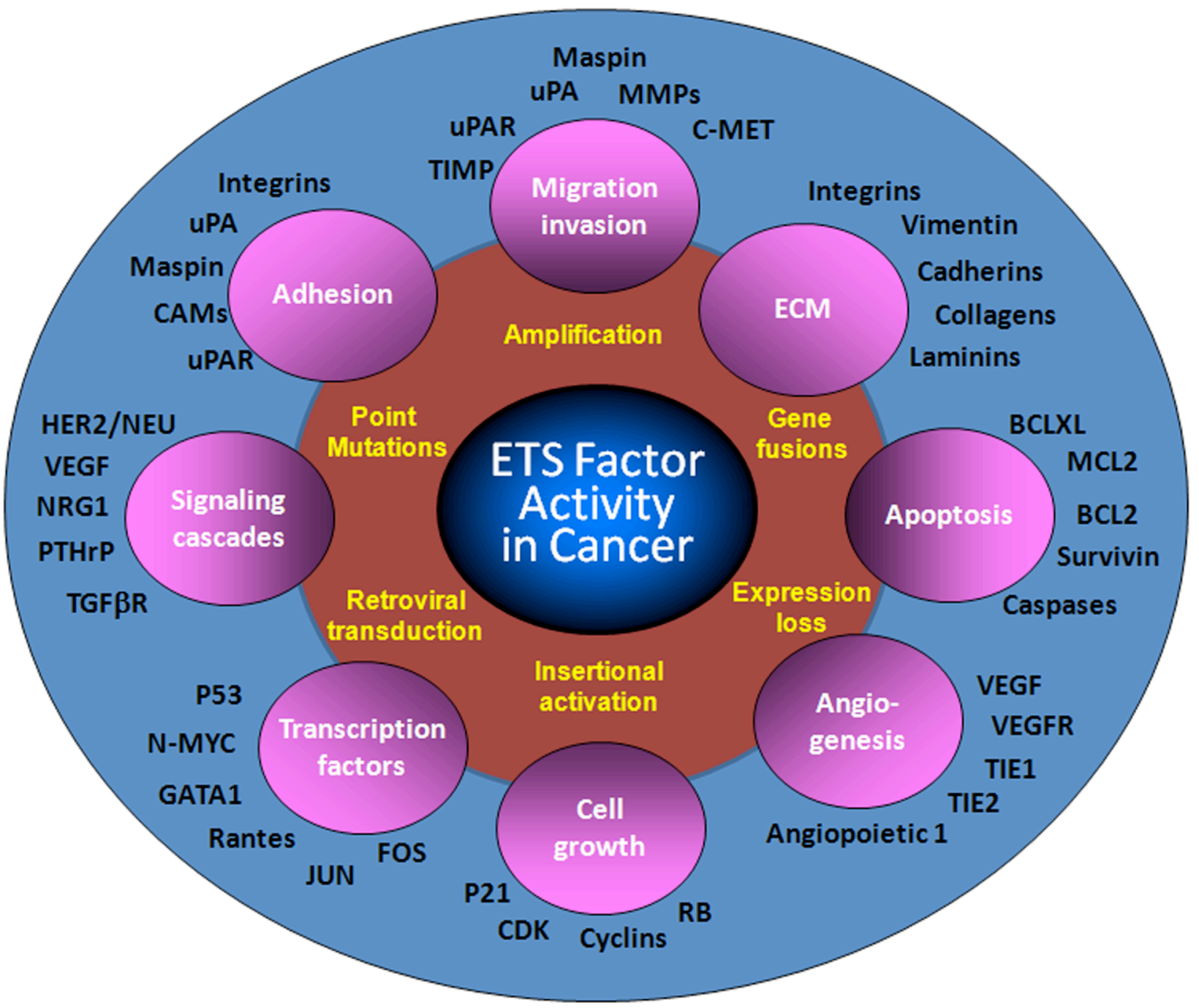

Fig. (2). ETS factors regulate the expression of genes associated with cancer progression. Dysregulated ETS factor function leads to the altered expression of multiple target genes that are known to play critical roles in many of the processes required for cancer progression. While each of the target genes highlighted have functional EBS(s) in their regulatory regions, the role and relative affinities of specific ETS factors has only been examined in a limited subset.

\section{ETS GENE EXPRESSION AND PROSTATE CANCER PROGRESSION}

Due to the complex heterogeneity of prostate cancer, accurate molecular analysis often requires methods that allow analyses of specific cells or cell types, including immunohistochemistry (IHC) and/or microdissection and subsequent RNA analysis. IHC requires highly specific antibodies and conclusions are best validated by using multiple antibodies for a given antigen. In part due to limitation of such highly specific antibodies, the expression pattern of only a few ETS factors has been explored during prostate cancer progression. Advanced stages of prostate cancer are associated with the increased expression of ETS1, ETS2, FLI1, ERG, ELF1, ESE2 and ER81, and the decreased expression or genomic loss of PEA3, ELK1, TEL, PDEF, and ESE3 (Table 2).

\section{ETS1}

An early IHC analysis of 25 high grade prostate tumors concluded that ETS1 protein was almost exclusively in the stroma of the tumors [11]. A subsequent study found that while all samples from normal prostate and benign prostatic hyperplasia cases were negative for ETS1 protein expression, increased cytoplasmic ETS1 mRNA and protein expression was reported for clinical and latent prostate cancer epithelium [12]. In addition to ETS-mediated transcriptional activation of multiple genes associated with cancer progression, additional mechanistic insights is provided by analysis of androgen receptor (AR) genomic targets demonstrated an enrichment of ETS transcription factor family and an interaction between the AR and ETS1 at a subset of the AR promoter targets was found [13]. These studies support the model that ETS proteins, including ETS1, regulate genes, including androgen response genes, which contribute to prostate cancer progression.

\section{ETS2}

Microdissection and RT-PCR demonstrated that ETS2 is over-expressed in nearly $40 \%$ (6 of 16) of patients with high Gleason-score primary and metastatic prostate cancers [14]. 
Table 2. Expression of ETS Family Members in Prostate Tissues

\begin{tabular}{|c|c|c|c|c|}
\hline Subfamily & Members & Unigene Name & Expression in Prostate Tissue & Reference \\
\hline \multirow[t]{5}{*}{ Ets } & ETS1 & ETS1 & Protein (IHC): over-expressed in tumor stroma & [11] \\
\hline & & & Protein (IHC): $77.0 \%(57 / 74)$ & {$[12]$} \\
\hline & ETS2 & ETS2 & RNA (RT-PCR): $6 / 16$ high Gleason-score primary and metastatic & [14] \\
\hline & & & Protein (IHC): 4/25 high grade cancer (gleason $>7$ ) & [11] \\
\hline & & & RNA (Microarray): higher in benign (average of 28 matched tissues) & [15] \\
\hline \multirow[t]{2}{*}{ Erg } & FLI1 & FLI1 & Protein (IHC): over-expressed 20/25 high grade tumors & {$[11]$} \\
\hline & ERG & ERG & Protein (IHC):over-expressed in 7/25 of the high grade cancers & {$[11]$} \\
\hline PEA3 & PEA3 & ETV4 & Protein (IHC): Negative staining / 25 tumors & {$[11]$} \\
\hline \multirow[t]{2}{*}{ Elf } & ELF-1 & ELF1 & Protein (IHC): over-expressed 16/25 high grade tumors & {$[11]$} \\
\hline & ELK1 & ELK1 & Protein (IHC): Negative staining / 25 tumors & [11] \\
\hline \multirow[t]{2}{*}{ TEL } & TEL & ETV6 & DNA: Genomic loss in 47\% (9/19) metastatic prostate cancers & {$[57,58]$} \\
\hline & & & DNA: Hemizygous deletion in 25\% TMPRSS2-ERG positive cancers & {$[43]$} \\
\hline \multirow{3}{*}{ ESE } & & & RNA (microarray): elevated $>2$ fold in $20 \%(2 / 9)$ tumor vs benign & {$[44]$} \\
\hline & ESE-3 & EHF & Protein (IHC) : reduced or lost & {$[54]$} \\
\hline & & & RNA (microarray, RT-PCR) and protein (IHC): Reduced expression & {$[55]$} \\
\hline
\end{tabular}

Listed are the major human ETS genes that have been found to be either over-expressed (black front) or under-expressed (white font on dark background) in prostate cancer. DNA (genomic), RNA (RT-PCR, in situ hybridization, microarray) or protein (IHC, Western blot) analyses indicated.

These results were subsequently confirmed at the protein level, where IHC analyses demonstrated that elevated ETS2 protein was observed in $16 \%(4 / 25)$ of tumors [11]. In contrast, a subsequent microarray analysis found reduced ETS2 mRNA expression prepared from sections of human prostate cancer [15]. The functional importance of the observed elevated ETS2 expression is supported by in vitro and in vivo studies. Specifically, antisense ETS2 or triplexDNA media-ted reduction of ETS2 mRNA and protein or dominant negative ETS2 over-expression reduces androgen indepen-dence, anchorage-independent growth, and tumorigenicity of prostate cancer cell lines [16, 17]. While dominant negative ETS2 protein may inhibit the function of multiple ETS factors [18], the similar results obtained from these multiple approaches support a role for ETS2 in prostate cancer progression.

\section{ERG}

ERG was found to be highly expressed in microdissected prostate tumor cells relative to benign tissues from over $60 \%$ of the 115 patients examined. Interestingly, ERG mRNA expression was highest in patients with less aggressive prostate cancers than in those with more aggressive tumors [19]. Consistent with the RNA based studies, ERG protein has been detected in adenocarcinoma cells of 7/25 high grade prostate cancers (Gleason $>7$ ) [11].

\section{FLI1 AND ELF1}

Although it has been reported that FLI1 and ELF1 proteins are over expressed in a limited number of prostatic 
adenocarcinomas relative to normal cells, additional mRNAand/or protein-based validation studies are required [11].

\section{ETS-FUSIONS IN PROSTATE CANCER}

A molecular mechanism to account for ERG overexpression in prostate cancer was subsequently provided by the identification of chromosomal rearrangements that result in the fusion between the $5^{\prime}$ end of the androgen-regulated, prostate specific transmembrane serine protease TMPRSS2 (21q22.2) gene to ERG (21q22.3) [20,21]. Collective studies show the TMPRSS2-ERG fusion is present in $40-80 \%$ of prostate cancers (recently reviewed in $[22,23]$ ). TMPRSS2ERG fusions occur either by chromosome translocation or by deletions between TMPRSS2 and ERG on chromosome 21, and deletions predominate, being observed in $60 \%$ of the TMPRSS2-ERG fusion positive cases [24]. It remains to be determined whether down-regulation of genes within the deleted region may modulate or be responsible for the poorer prognosis of patients with fusions generated by deletion rather than translocation. Furthermore, the possible impact of loss of normal ERG expression has not been explored. A complex pattern of 17 different TMPRSS2-ERG fusion mRNA transcripts have been characterized [21, 24, 25]. Nine of these transcripts are predicted to make protein: 2 encode normal ERG proteins, 6 encode $\mathrm{N}$-terminal truncated ERG proteins, but only one protein is predicted to encode a TMPRSS2-ERG fusion protein $[25,26]$. ERG fusion transcripts were also detected in $6 \%$ (2 of 31) $\mathrm{BPH}$ specimens [25] and in $21 \%$ (4 of 19) of high-grade prostatic intraepithelial neoplasia (HGPIN) [27], supporting the model that the fusion can be an early event during prostate cancer development.

TMPRSS2-ERG fusion prostate cancer has been associated with five morphological features associated with aggressive prostate cancer: blue-tinged mucin, cribriform growth pattern, macronucleoli, intraductal tumour spread, and signet ring cell features. This study also demonstrates an association between a specific molecular alteration and distinct phenotypic features of prostate cancer [28]. Patients with ERG rearranged tumors have poor outcome [29, 30] and specific subclasses among these chromosomal rearrangements may indicate worse prognosis. For example, 2+Edel, which has duplication of TMPRSS2:ERG fusion sequences, defines patients with particularly poor survival [29]. An 87 gene signature has been associated with TMPRSS2:ERG fusion tumors [31]. Collective data suggest the TMPRSS2ERG fusions define a subset of prostate cancer and specific fusions predict poor prognosis and survival.

Gene fusions involving other ETS transcription factors ETV1 (7p21.2), ETV4 (17q21), or ETV5 (3q28) have been identified in prostate cancer. However, TMPRSS2-ERG fusion and mRNA over-expression accounts for the majority of cases [20, 32-36]. Each of these fusions results in androgen-induction of various ETS factors, which are then thought to activate a repertoire of ETS-responsive genes, leading to prostate cell transformation. ETS fusion with other androgen-regulated gene promoters has been found in prostate cancer. Among these, SLC45A3-ELK4 (ERM) is expressed in both benign prostate tissue and prostate cancer [37].
Possible mechanistic insights are provided by observation that TMPRSS2-ERG fusion activates MYC and abrogates prostate epithelial differentiation [38]. Expression of an ERG fusion into primary or immortalized benign prostate epithelial cells induced an invasion-associated transcriptional program, but did not increase cellular proliferation or anchorage-independent growth. These results suggest that TMPRSS2-ERG may be necessary but not sufficient for transformation in the absence of secondary molecular lesions [39]. In vitro over-expression of ERG promotes cell migration, a property necessary for tumorigenesis, without affecting proliferation [40] and over-expression of ERG in prostate cell lines has also been associated with increased cell invasion [41].

\section{ER81 (ETV1) and ERM (ETV5)}

ETV1 is over-expressed in prostate cancer independent of the TMPRSS2-ETV1 translocation. Inhibition of ETV1 expression in prostate cancer cells reduces their invasion capacity, supporting an important role for ETV1 in prostate cancer metastasis [42].

ETV5 over-expression induces invasion in RWPE cells, a benign immortalized prostatic epithelial cell line. Expression profiling and an integrative molecular concepts analysis of RWPE-ETV5 cells also revealed the induction of an invasive transcriptional program [34].

\section{ALTERATIONS OF ETS GENES IN PATIENTS WITH ERG OVER-EXPRESSION}

Copy number alterations for ETS2 (21q22), TEL (12p13), FEV (2q23), ELF1 (13q13) and ERF (19q13) were recently identified in prostate cancer cells harboring TMPRSS2-ERG fusions [43]. Gathering evidence supports the model that altered ETS factor expression occurs in prostate tumors that do not over-express ERG; thus, an inverse relationship may exist between ERG expression and other ETS factor expression.

Analysis of microarray expression data for 20 ETS factors found that, in contrast to ERG, most ETS factors were not elevated in prostate cancer compared to matched benign tissue. Interestingly, 30\% (3/9) of patients without ERG over-expression were found to over-express ELF5. Further-more, ETV1 and ETS1 were abundantly expressed in some cases lacking ERG over-expression. It was hypothesized that such ETS factors may substitute for ERG [44].

\section{NEGATIVE REgULATORS OF PROSTATE CARCINOGENESIS - TUMOR SUPPRESSOR GENES}

In addition to the initial elucidation of ETS as oncogenic transcription factors, recent studies support a role for ETS factors functioning to suppress cellular growth, migration and/or invasion, suggesting possible tumor and/or metastasis suppressor functions.

\section{PDEF}

The PDEF gene is expressed in the normal prostate and its over-expression at the mRNA level has been demons- 
trated for aggressive prostate tumors. However, in prostate [45], as well as other cancer types [46, 47], PDEF mRNA level is not always correlated with protein level. Comparative in situ hybridization and IHC demonstrated that PDEF protein is lost in prostate cancer cells that retain mRNA expression [45]. Furthermore, PDEF protein is lost in most prostate cancers examined by IHC $[45,48]$. In contrast, another IHC study found that PDEF protein expression was increased in $27 \%, 33 \%$, and $40 \%$ of benign prostate tissues, PIN samples, and prostate adenocarcinomas, respectively. In matched samples of cancer vs. benign and cancer vs. PIN, $68 \%$ and $70 \%$, respectively, showed increased expression in the malignant tissue [49].

Relevant to prostate specific gene expression, PDEF has been shown regulate the PSA promoter independent of the androgen receptor. PDEF and AML/RUNX [50] co-regulate the PSA promoter. In addition, PDEF interacts with the DNA binding domain of the androgen receptor to enhance androgen-dependent activation of the PSA promoter [51]. In contrast, PDEF interacts with the tumor suppressor NKX3.1, which represses PSA expression [52]. In vitro studies using $\mathrm{PC} 3$ and $\mathrm{LNCaP}$ prostate cancer cells have demonstrated the anti-migratory and anti-invasive properties of PDEF, in part by negative regulation of mesenchymal genes [53]. Inhibition of PDEF was associated with change from epithelial properties toward mesenchymal phenotypes, suggesting that PDEF is a negative regulator of the epithelial-mesenchymal transition (EMT). The functional studies support the model that loss of PDEF protein contributes to prostate cancer progression.

\section{ESE3}

ESE3 is reduced at the RNA and protein level in prostate cancer clinical samples compared to normal prostate [54]. ESE3 is a transcriptional repressor of ETS/AP1 regulated genes, including matrix metalloproteinase 1 (MMP-1) [54]. In PC3 and DU145 cells, ESE3 is found to be epigenetically silenced by promoter methylation. Functional studies demonstrated that re-expression of ESE3 in prostate cancer cells inhibited clonogenic survival and induced apoptotic cell death [55]. In contrast, ESE3 over-expression in PC-3 cells has been associated with decreased senescence and increased drug resistance and reciprocal knockdown reduced tumor growth in vivo [56]. Future studies are needed to resolve this apparent conflict.

\section{TEL}

Nearly half of metastatic prostate cancers show $12 \mathrm{p} 12-13$ loss of heterozygosity (LOH) [57]. Within this region, homozygous deletion [58] and mutation [59] of TEL (12p13) has been demonstrated. The functional significance of TEL in prostate cancer remains to be experimentally assessed.

\section{MOUSE ETS MODELS FOR PROSTATE CANCER}

In vivo gain of function and loss of function studies are needed to establish ETS factor functionality and also provide mechanistic insights. Several studies have demonstrated a causal role for ETS fusion proteins in prostate cancer progression. Specifically, transgenic mice expressing truncated ETV1 under the control of the androgen responsive probasin promoter (ARR2Pb-ETV1) developed mouse prostatic intraepithelial neoplasia (mPIN) [33]. Two independent studies have shown that mice expressing ERG gene fusion products under the probasin promoter developed mPIN [39, 41]. In contrast, subsequent studies from other laboratories concluded that expression of ERG did not result in mPIN $[60,61]$. Differences in the exact transgenic protein expressed, site of integration, level of transgene expression and other parameters may be responsible for the presence or absence of MPIN in the specific models.

Based upon the observation that prostate cancer specimens containing the TMPRSS2-ERG fusion are often enriched for loss of the tumor suppressor gene PTEN, the impact of PTEN loss upon ERG-mediated phenotypes has recently been examined in mice. Transgenic over-expression of ERG in mouse prostate tissue promotes marked acceleration and progression of high-grade prostatic intraepithelial neoplasia (HGPIN) to prostatic adenocarcinoma in a PTEN heterozygous background $[40,61]$.

\section{ETS GENE EXPRESSION AND BREAST CANCER PROGRESSION}

Several ETS factors are deregulated in the development of breast cancers. As described above for prostate cancer, different ETS factors are either over-expressed or show reduced expression in breast cancer. While elevated expression is found for several ETS factors (e.g., ETS1, ETS2, PEA3, ERM, ESE1), the expression of other ETS factors (PDEF, ESE3) is reduced or lost during breast cancer progression (Table 3 ).

\section{ONCOGENIC ETS FACTORS}

\section{ETS1}

Multiple investigators have used in situ hybridization, mRNA analysis, and/or IHC to show that ETS1 is increased in invasive breast cancers relative to in situ lesions. ETS1 expression observed in endothelial cells and stromal fibroblasts was up-regulated in the stroma of invasive ductal and lobular cancers. Expression of ETS1 was also found within epithelial cells of both in situ and invasive breast carcinomas. Furthermore, the observed ETS1 up-regulation was associated with MMP1 and MMP9, supporting a role in both angiogenesis and tumor cell invasion [62].

Real-time quantitative PCR analysis demonstrated ETS1 mRNA in $62 \%$ cases of sporadic breast cancer. While expression was not found to be correlated with several established clinico-pathological factors (tumor size, type and grade; ER, PR level), ETS1 expression showed significant prognostic value for relapse-free survival. Thus, ETS1 is a strong, independent predictor of poor prognosis in breast cancer [63].

ETS1 mRNA was detected by RT-PCR in 30 out of 42 (71\%) fibroadenomas and 131 out of $179(73 \%)$ primary breast carcinomas. While ETS1 mRNA was found at similar levels in fibroadenomas and primary breast carcinomas, higher ETS1 protein levels were detected in the cancers compared to the benign specimens. Similar to the results described above, this study found that ETS1 mRNA and 
Table 3. Expression of ETS Family Members in Breast Tissues

\begin{tabular}{|c|c|c|c|c|}
\hline Subfamily & Members & Unigene Name & Expression in Breast Tissue & Reference \\
\hline \multirow[t]{6}{*}{ ETS } & ETS1 & ETS1 & $\begin{array}{l}\text { RNA (in situ) and protein (IHC): Expressed in endothelial cells, fibroblasts and } \\
\text { epithelium of DCIS ( } \mathrm{n}=13) \text { and invasive cancer }(\mathrm{n}=21)\end{array}$ & {$[62]$} \\
\hline & & & $\begin{array}{c}\text { RNA (RT-PCR) detected in } 71 \%(30 / 42) \text { fibroadenomas and } 73 \%(131 / 179) \\
\text { primary breast carcinomas }\end{array}$ & {$[64]$} \\
\hline & & & Protein ( IHC): expression in $52 \%$ stage I/II breast cancer $(n=134)$ & {$[66]$} \\
\hline & & & $\begin{array}{c}\text { Protein (IHC): expression in } 83 \%(104 / 137) \text { cancers; not detected in normal or } \\
\text { non-invasive cancer }\end{array}$ & {$[65]$} \\
\hline & ETS2 & ETS2 & $\begin{array}{l}\text { RNA (in situ) over-expressed in } 35 \% \text { non-invasive }(\mathrm{n}=41) \text { and } 57 \%(\mathrm{n}=33) \\
\text { invasive }\end{array}$ & [78] \\
\hline & & & Protein (WB); Ets 2 protein was detected in $85-89 \%$ of breast cancers & [73] \\
\hline \multirow[t]{5}{*}{ PEA3 } & PEA3 & ETV4 & $\begin{array}{c}\text { RNA (in situ) over-expressed } 93 \% \text { (43/46) Her2 positive ; } 46 \% \text { (13/28) Her2 } \\
\text { negative }\end{array}$ & [78] \\
\hline & & & RNA (RT-PCR) over-expression (14\%) and down-regulation $(23 \%)(n=130)$ & {$[81]$} \\
\hline & & & $\begin{array}{c}\text { Protein (IHC): expression } 47 \% \text { of the breast tumors; no expression in normal and } \\
\text { non-tumor }\end{array}$ & [82] \\
\hline & & & Protein (IHC): expression $22.2 \%(64 / 289)$ of the breast tumors & {$[83]$} \\
\hline & ERM & ETV5 & RNA (RT-PCR) detected in $79 \%$ at a threshold value above $0.05(\mathrm{n}=364)$; & [89] \\
\hline \multirow[t]{5}{*}{ PDEF } & PDEF & SPDEF & $\begin{array}{c}\text { RNA (RT-PCR): Elevated expression in cancer (14-16/20) compared to normal } \\
\text { breast tissue }\end{array}$ & {$[125]$} \\
\hline & & & RNA (RT-PCR): Elevated in $74 \%(64 / 86)$ & {$[98]$} \\
\hline & & & Protein (IHC): expression reduced in cancer compared to non-tumor $(\mathrm{n}=17)$ & [99] \\
\hline & & & Protein (IHC): not expressed in basal subtype $(\mathrm{n}=16)$ & {$[103]$} \\
\hline & & & $\begin{array}{l}\text { Protein (IHC): expressed in 74\% (20/27) luminal, } 100 \% \text { (6/6) apocrine, } 91 \%(21 \\
\text { /23) HER2/neu + }\end{array}$ & [103] \\
\hline ESE & ESE-1 & ELF3 & $\begin{array}{l}\text { RNA (in situ hybridization): over-expressed in HER2/neu positive DCIS ( } \mathrm{n}=10) \\
\text { compared to normal }(\mathrm{n}=3)\end{array}$ & {$[90]$} \\
\hline
\end{tabular}

Listed are the major human ETS genes that have been found to be either over-expressed (black front) or under-expressed (white font on dark background) in breast cancer. DNA (genomic), RNA (RT-PCR, in situ hybridization, microarray) or protein (IHC, Western blot, WB) analyses indicated.

protein expression was not correlated with tumor size, nodal status, histology type ER or PR levels. However, ETS1 protein expression was correlated with urokinase plasminogen activator (uPA) and HER2/neu, predictors of aggressiveness [64].

Consistent with ETS1 expression patterns described in the above studies, additional IHC analysis demonstrated that while ETS1 was not expressed in the normal breast epithelium nor in noninvasive carcinomas, 83.2\% (104/137) breast carcinoma patients showed positive staining for the ETS1 protein. Histologically, invasive ductal carcinomas expressed immune-positivity with intense staining for ETS1 in the tumor cells. In this study, ETS1 expression was correlated with Bloom-Richardson grading in invasive ductal carcinoma $(\mathrm{p}<0.01)$; however, there was no correlation between ETS1 expression and lymph node metastasis [65].

Supporting this general pattern of over-expression in breast cancer, another study showed that ETS1 protein is expressed in $52 \%$ of breast tumor patients. Furthermore, ETS1 protein level was associated with time to disease recurrence in breast tumor patients [66]. 
These collective findings support the conclusion that ETS1 is over-expressed in cells of the breast that have undergone malignant conversion and that ETS1 is one of the factors associated with tumor growth. In human breast cancer cell lines, ETS1 expression has been correlated with cell invasiveness and EMT, concomitant with expression of uPA, MMP1, MMP3 and vimentin and loss of E cadherin [67].

The impact of ETS1 on phenotypes and molecular regulation in breast cancer cells has been demonstrated through in vitro gain-of-function (over-expression of ETS1), as well as loss-of-function (ETS1 DNA binding domain (dominant negative), antisense and siRNA against ETS1) experiments. Over-expression of ETS1 in MCF7 cells increases expression of MMP1 and expression of MMP-1 was down-regulated by the addition of ETS1 siRNA to the MDA-MB-231 cell line. ETS1 also enhanced HER2induction of MMP1 expression [68]. Dominant negative ETS1 inhibits CXCR4 mediated cell invasion, supporting a role for ETS1 and/or other ETS factors [18], in promoting metastasis of breast cancer cells [69]. Expression of ETS1 has been shown to increase migration and invasion of mouse mammary tumor (MMT) epithelial cells and promote expression c-Met, altered integrin expression patterns, and MMP expression and activation [70].

Several proteins that interact with ETS1 have been show to inhibit ETS1 transcriptional activity [71, 72]. Inhibiting ETS1 function by expression of one of these proteins, SP100, inhibits MMP1 and uPA expression and breast cancer cell invasion [72].

The collective clinical observations and functional studies support a critical role for ETS1 in the regulation of the network of molecular and phenotypic events that regulate cellular migration and invasion, malignant features of mammary cancer cells. Thus, ETS1 over-expression is among the key steps that are necessary for breast cancer progression.

\section{ETS2}

ETS2 protein was found to be expressed in $54 \%$ of breast tumor patients and ETS2 protein levels are significantly associated with time to disease recurrence in breast tumor patients [66]. These findings were confirmed by RT-PCR and western blot analysis of breast cancer compared to normal tissues. ETS2 mRNA expression was found to be higher in fibroadenoma $(n=43)$ and primary tumors $(n=181)$ compared to normal breast $(n=43)$. Significantly, ETS2 protein was higher in primary tumors $(\mathrm{n}=111)$ compared to both fibroadenomas $(n=38)$ and normal breast tissue $(n=11)$. In addition, positive correlation was found between ETS2 protein and uPA expression [73].

ERK1/2 phosphorylation enhances transcriptional activity of multiple ETS factors, including ETS2. One report found that ERK1/2 phosphorylation (activation) was found in $46 \%(136 / 293)$ breast cancer patients. ETS2 phosphorylation was found in $69 \%(175 / 253)$ of the patients. ERK phosphorylation and ETS2 phosphorylation were correlated. Both ERK1/2 and ETS2 phosphorylation were inversely correlated with tumor size in breast cancer patients [74]. That ERK1/2 and ETS2 phosphorylation correlate with better survival in untreated patients suggests that it may be associated with less aggressive breast cancer. ERK phosphorylation was also found in stromal cells in $57 \%$ $(165 / 289)$ of the cases examined. As will be described below, studies with murine models support the model that Ets2 dosage in stromal cells affects breast tumor initiation and not tumor growth. Based upon these observations, examination of ETS2 phosphorylation in non-epithelial cells is warranted.

Support for a functional role of ETS2 has been provided by the ability of dominant negative (DNA binding domain) ETS2 to inhibit cell invasion and reverse the transformed phenotype of BT20 breast cancer cells [75]. As noted above, this approach is likely to inhibit the binding and resultant function of multiple ETS factors [18]. Reducing ETS2 by gene silencing has been correlated with reduced hTERT expression and cell proliferation and increased cell death, supporting the model that ETS2 is also required for breast cancer cell growth [76]. In addition to being an activator of pro-cancer genes, ETS2 has been shown to be a repressor of tumor suppressor genes. For example, ETS2, with components of the mammalian SNF/SWI complex, functionally represses transcription of the tumor suppressor gene, BRCA1 [77].

\section{PEA3}

PEA3 mRNA expression was examined in normal breast tissue $(n=5)$, ductal carcinoma in situ (DCIS, $n=43)$ and invasive human breast tumors $(\mathrm{n}=33)$. While PEA3 mRNA expression was low or undetectable in normal tissue, overexpression of PEA3 mRNA was correlated with HER2/Neu receptor positivity, an early event in the genesis of human breast cancer [78]. Less than half of the HER2/Neu-negative tumors, whether invasive or not, over-expressed PEA3. PEA3 transcripts are increased in 93\% of HER2/Neu-overexpressing human breast tumor samples. In contrast to PEA3, ETS2 was not associated with HER2/Neu in the same samples, indicating the specificity of HER $2 / \mathrm{Neu}$ association with PEA3 [78].

PEA3 mRNA has been found to be significantly upregulated in malignant effusions compared to primary breast tumors. Expression was seen in 19 out of $40(48 \%)$ of solid lesions (primary tumor and metastasis), with a significant up-regulation in corresponding effusions compared to primary tumors (24 out of 33) [79]. A subsequent study confirmed the finding that PEA3 mRNA is expressed more highly in pleural effusions, concomitant with elevated MMP2 [80].

A subsequent study failed to find a comparable extent of PEA3 over-expression. Among 130 patients with invasive breast cancer, both over-expression (14\%) and downregulation $(23 \%)$ of PEA3 were observed. In this study, high PEA3 mRNA levels relative to normal ductal cells correlated with Scarff-Bloom-Richardson (SBR) histopathological grade III, but not with poor prognosis, suggesting that PEA3 could be a marker of tumor aggressiveness rather than a prognostic factor in human breast cancer [81].

Expression of PEA3 protein in breast tumors from patients of known HER2 status $(\mathrm{n}=107)$ was examined by IHC. While not detected in tissue from reduction mammoplasties or matched non-tumor breast samples, PEA3 protein was expressed in $47 \%$ of the breast tumors. PEA3 protein 
expression was correlated with grade III tumors, HER2 status, auxiliary lymph node metastasis, and reduced diseasefree survival [82].

Another study found PEA3 protein expression in 22.2\% (64/289) of breast cancers, but failed to find correlation with HER2/neu expression [83].

Collectively, the results from most of the RNA based analysis are confirmed at the protein level, and support the model that up-regulation of PEA3 expression is associated with aggressive cancer and poor patient outcome.

Both PEA3 and another PEA3 family member ER81 are downstream targets of HER2/Neu [78, 84]; thus, ETS factors are both upstream regulators and downstream effectors of HER2/neu signaling. The HER2/neu promoter was shown to have a functional EBS located within a DNase1 hypersensitive site [85] and recent chromatin immunoprecipitation (ChIP) studies demonstrated that PEA3 is bound to the HER2/neu promoter in vivo [86]. Functional studies demonstrate that PEA3 expression in the non-invasive breast cancer cell line MCF-7 increased migration and invasion and MMP9 expression. Furthermore, tumors derived from the PEA3 expressing MCF7 cells were highly invasive and produced MMP9 [87]. In addition to promoting cell migration and invasion, PEA3 over-expression in MDA-MB-231 breast cancer cells increased cell cycle progression, cyclin D3 transcription and in vivo tumor growth. Reciprocal PEA3 and cyclin D3 RNAi knockdown studies confirmed that the pro-proliferative function was mediated by cyclin D3 expression [88].

\section{ERM}

The related PEA3 family gene ERM may also be clinically relevant as its expression may be an independent predictor of prognosis. Real-time RT-PCR was used to analyze ERM mRNA in 364 unselected primary breast cancers. ERM was positively correlated to EGFR and histological grading, whereas it was negatively correlated to estrogen receptors, and HER3 and HER4. Significantly, in this study ERM gene expression was associated with poor overall survival in breast cancer patients [89].

\section{ESE1}

ESE1 is located at chromosome 1q32 in a region amplified in $50 \%$ of early breast cancers. ESE1 mRNA is overexpressed in DCIS, an early stage of human breast cancer development [90]. ESE1 is heregulin-inducible and overexpressed in HER2/neu activated breast cancer cells. ESE1 can transform MCF-12A human mammary epithelial cells, as shown by increased colony formation [91]. ESE1 expression also resulted in EGF-independent cellular proliferation, growth in soft agar, increased cell adhesion, motility and invasion and an epithelial to mesenchymal (EMT) morphological transition [92]. ESE1 is an activator of multiple ETS target genes, including HER2/neu and MMP1 [91].

\section{TEL (ETV6) FUSION}

The product of the $\mathrm{t}(12 ; 15)(\mathrm{p} 13 ; \mathrm{q} 25)$ translocation is characteristic of human secretory breast cancer (SBC), a rare subtype of infiltrating ductal carcinoma [93]. This translocation generates a gene fusion, ETV6-NTRK3, which encodes a chimeric protein made up of the oligomerization domain of TEL (ETV6) and the protein tyrosine kinase (PTK) domain of NTRK3 (also known as TRKC, a TRK family tyrosine kinase receptor for neurotrophin-3). ETV6NTRK3 expression was confirmed in 92\% (12/13) of SBC cases, but not in other ductal carcinomas. Functionally, ETV6-NTRK3 has been shown to transform Eph4 and Scg6 murine immortalized non-transformed mammary epithelial cells in vitro and to establish tumor growth in vivo [94]. These findings establish ETV6-NTRK3 as an oncogene in SBC.

ETV6 gene rearrangements have been found in a limited number of invasive breast carcinoma specimens ( 5 of 356 : FISH) [95]. The role of other ETV6 rearrangements as well as ETV6 itself on cancer progression remains to be examined.

\section{NEGATIVE REGULATORS OF BREAST CARCINO- GENESIS - TUMOR SUPPRESSOR GENES}

\section{PDEF}

PDEF was found to be present at higher frequencies in the cDNA libraries prepared from brain, breast, lung and ovarian tumors compared to libraries from the corresponding normal tissues [96]. PDEF mRNA was subsequently found to be over-expressed in the majority of atypical ductal hyperplasia (ADH), DCIS and invasive ductal carcinoma (IDC) samples examined [97]. In a study of a large patient cohort, PDEF mRNA over-expression was associated with moderate to well-differentiated (grades I and II) ER-positive breast cancers, with hormone receptor positivity (estrogen and/or progesterone), and with metastatic nodal involvement at the time of surgery. No association was found between PDEF mRNA expression and patient age, tumor size, ductal, or lobular histological type [98].

As noted for prostate cancer, PDEF mRNA and protein levels are not always correlated in breast cancer. Early studies demonstrated that PDEF protein is reduced or lost in breast cancer [46]. In a subsequent study, PDEF protein expression was reduced or lost in $100 \%(17 / 17)$ of cancer tissues; here, the percentage of loss of PDEF expression was greater in the higher grade tumors $(3 / 6,50 \%)$ as compared with the lower grade tumors $(0 / 60 \%)$. Furthermore, this study supported a negative correlation between PDEF expression and disease progression/recurrence [99]. In contrast, increased expression of PDEF protein expression was identified in $18 \%(11 / 62), 50 \%(23 / 46), 46 \%(30 / 65)$, and $51 \%(20 / 39)$ of benign breast tissues, intraductal, invasive ductal, and invasive lobular carcinomas, respectively. In another set of 9 matched tumor and benign breast tissues, $90 \%$ (8/9) showed higher expression of PDEF in the tumor tissue. Although PDEF expression was higher in cancer than benign tissue in this study, it should be noted that $54 \%$ and $49 \%$ of invasive ductal, and invasive lobular carcinomas showed no or low staining [49].

These studies demonstrate that PDEF protein can be present, reduced or absent from human breast cancer samples, perhaps reflecting the observation that breast cancer is a 
very heterogeneous disease. Microarray profiling has molecularly defined at least five molecular subtypes of breast cancer: luminal subtypes A and B, ERBB2, basal and normal breast like [100]. The subsets of tumors show unique patterns of transcriptional, genomic and biological phenotypes. A recent study of 51 breast cancer cell lines and 145 primary breast tumors demonstrated that the recurrent genomic and transcriptional characteristics of breast cancer cell lines mirror many of those found in the primary breast tumors. However, the two luminal subsets evident in tumors were not apparent in the cell lines, and the basal-like cell lines resolved into two distinctive clusters (Basal A and Basal B) that are not apparent in analyses of primary tumors. PDEF, as well at other genes associated with a more differentiated, non-invasive phenotype, were preferentially expressed in the luminal cell lines [101].

ER-negative, progesterone receptor-negative (ER(-)/ PR(-)) breast cancer represents approximately $25-30 \%$ of all breast cancers and generally has a more aggressive clinical course. PDEF mRNA and protein was found to be expressed in the subset of $\mathrm{ER}(-) / \mathrm{PR}(-)$ breast tumors that retain expression of genes that are either direct targets of ER or responsive to estrogen. Among 41 double negative tumors examined by microarray analysis, two major molecular subtypes were found: one composed of 10 samples with a molecular features common to $\mathrm{ER}(+)$ breast cancer (ER(-) class A) and another composed of the remaining 31 breast cancers (ER(-) class B). The ER(-) class A molecular phenotype is associated with androgen responsive genes. PDEF mRNA and protein expression was retained in class A (10/10), but lost/reduced in class B (31/31), which represented the majority of double negative breast cancer samples [102].

In a recent study, PDEF protein expression was lost in $100 \%(16 / 16)$ breast tumors of the basal subtype. In contrast, 20 of $27(74 \%)$ of ER-positive/Her2-negative tumors (luminal), 6 of $6(100 \%)$ of apocrine tumors, and 21 of 23 (91\%) Her2-positive tumors expressed PDEF [103].

Gain-of-function (re-expression) studies have demonstrated that PDEF is a negative regulator of breast cancer cell growth [46]. PDEF has been found to inhibit [46, 104, 105] or enhance [97] cellular migration and invasion in vitro. Reciprocal loss-of-function RNAi studies show that reduction of PDEF expression increases migration of breast cancer cells [104]. Reduced PDEF expression also increases MCF-7 cell growth in vitro and xenograft tumor growth in vivo, concomitant with up-regulation of survivin [99]. PDEF is a negative regulator of $\mathrm{UPA}$ and a positive regulator of maspin [46]. Gain and loss studies demonstrated an inverse correlation between PDEF and the anti-apoptotic protein survivin [99]. Global expression profiling following PDEF expression in three breast cancer cell lines identified focal adhesion, adherens junctions, cell adhesion and actin cytoskeleton regulation as cell migration associated interaction pathways significantly impacted by PDEF expression [105]. Significantly, ChIP analysis demonstrated that PDEF is a direct negative regulator of the metastasis associated gene uPA and phenotypic rescue experiments demonstrate that exogenous uPA expression can restore the migratory ability of invasive breast cancer cells expressing PDEF [105].
Taken together, these findings support the model that PDEF is a negative regulator of breast cancer progression.

\section{ESE-3}

ESE3 is located on chromosome $11 \mathrm{p} 12$, a region that is often deleted in prostate, breast, and lung carcinomas [106]. While ESE3 protein is expressed in normal breast epithelium, protein expression was lost in the single breast cancer specimen examined [54]. These observations provide the rationale for additional IHC analyses.

\section{ETS TRANSGENIC MICE}

\section{PEA3 Family}

Three genes of the PEA3 subfamily (Pea3, Er81, and Erm) are coordinately over-expressed in mammary tumors of MMTV-neu transgenic mice. An in vivo functional role is supported by the observation that expression of a dominantnegative PEA3 transgene under the control of the MMTV promoter in mammary epithelial cells of MMTV-neu transgenic mice delayed the onset and reduced the number and size of mammary tumors [107]. As noted above, such dominant-negative approaches are likely to compete with multiple ETS factors.

\section{ETS2}

The role of Ets 2 in murine mammary tumor development has been explored using several constitutive and conditional Ets2 knockout mouse models. Ets2 dosage was found to affect mammary tumor development in the MMTV-PyMT (polyoma middle T) model. While all mice expressing PyMT developed tumors, tumors that arose in mice with a single Ets2 copy (Ets2 heterozygotes) were significantly smaller. Once initiated, tumor growth in wild-type and heterozygous Ets2/MMTV-PyMT was similar, suggesting that Ets2 dosage affected tumor initiation and progression rather than growth rate [108]. In such constitutive Ets2 knockout mice, Ets2 is absent in all epithelial and stromal tissues. To examine the role of Ets expression in specific cellular compartments, the impact of epithelial specific Ets2 deletion on mammary tumor formation was subsequently examined by MMTVCre 7 mediated deletion in mice with Ets2 conditional alleles. While mammary tumor development was not influenced by Ets2 deficiency in epithelial cells, nearly complete loss of Ets2 in the adult mouse was associated with a delay of tumor onset. As noted with constitutive Ets2 deletion, once tumors appeared, their rate of growth was not significantly altered by ubiquitious deletion [109]. These observations support the notion that stromal Ets2 expression regulates the initiation and progression of mammary epithelial tumor development.

\section{ETV6-NTRK3}

An oncogenic role for the ETV6-NTRK3 fusion product associated with a subset of human breast cancers has been demonstrated in vivo. Expression of a knockin transgene was achieved by WAP-Cre mediated gene activation, resulting in multifocal cancer [110]. Expression of a dominant negative c-Jun blocked tumorigenesis, supporting the role of AP1 (c- 
Jun/Fos) activation in mediating transformation in this model.

\section{ETS CONVERSION}

To date, ETS research has mainly focused on the molecular mechanisms and functions of individual transcription factors and has produced insights into ETS factor function in both normal and cancer cells. In many cells, multiple ETS factors with similar or opposite functions are present simultaneously and the cell's fate may depend ultimately on the balance between the activities of distinct ETS factors.

A limited number of studies have examined the expression of multiple ETS factors in normal prostate or breast tissue and respective cancers. When interpreting RNA based studies, it is important to note that RNA and protein expression are often not correlated, as has been shown for PDEF by comparative in situ hybridization and immunohistochemical analysis of cancer tissue [45], as well as Northern, real-time RT-PCR, and western blot analysis of cell lines [46, 111]. At least one mechanism that contributes to this phenotype has been provided by a recent study that identified two microRNAs that directly act on and repress PDEF mRNA translation, leading to the loss of PDEF protein expression and the gain of phenotypes associated with invasive cells [111].

\section{Prostate}

As discussed for individual ETS factors above, an initial IHC evaluation of protein expression of seven ETS family members in 25 high-grade prostate cancers (gleason $>7$ ) and 4 benign prostatic samples [11] was performed. This study concluded that two ETS family members (FLI1 and ELF1) are highly expressed in adenocarcinoma cells of the majority of cancers, while two others (ERG and ETS2) were expressed in a minority of cancers. In contrast, ELK1, PEA3 and PU.1 were minimally expressed [11]. While this supports the notion of differential ETS factor expression, the patterns observed are not consistent with some studies which examined the expression of individual factors (see above and Table 2).

RNA expression data for 27 human ETS genes were determined for the 14 advanced prostate cancer samples. ERG was the most frequently up-regulated ETS factor in advanced prostate tumors, including both hormone-refractory (4/9) and untreated clinically advanced prostate cancers $(2 / 5)$. Expression of the ETS factors was not consistently associated with hormone-refractory tumors [112].

\section{Breast}

Transcripts for 24 of 25 murine Ets factors are detected in normal mouse mammary tissue [113]. Since mammary tissue is composed of multiple cell types, it was also demonstrated that two cell lines derived from normal mouse mammary epithelium ( $\mathrm{NMuNg}$ and $\mathrm{HC11}$ ) retained expression of 14-20 Ets factors. Ets factor expression in normal mammary tissue was compared with mammary tumors isolated from three transgenic mammary tumor models. The largest degree of tumor/normal increased expression was observed in the Pea3 subfamily (Pea3, Er81, and Erm). Elevated RNA expression was also found for
Ese1, Pdef, Ese2, Ese3, Tel, and Nerf was also found in mammary tumors.

Transcripts for each of the 27 human ETS genes was measured by real-time RT-PCR of RNA prepared from human breast cell lines. No detectable transcripts from ERF, ETV2, FEV, SPI1, SPIB or SPIC were detected in any of the cell lines examined. Of the 21 detectable genes, 14 were expressed at a similar level in both normal and breast cancer cell lines or did not show a consistent pattern of differential expression. Four genes, ESE3 (EHF), ESE1 (ELF3), ESE2 (ELF5) and PDEF, were expressed at higher levels in breast cancer cells than normal epithelial cells. The expression of ELK3, ETS1 and FLI1 were reported to be reduced in breast cancer cells [114]. This pattern defined in cell lines does not absolutely correlate to that observed in tissue specimens. As noted above, ETS1 is over-expressed and PDEF protein is often reduced or lost in human breast cancer. While further studies are needed, ESE3 protein was absent in one breast cancer sample examined by IHC.

\section{ETS Regulatory Network}

Collectively, the results from this limited set of studies support two overall conclusions: (1) Multiple ETS factors are simultaneously expressed in prostate and breast cells; (2) While some ETS factors are over-expressed in cancer cells, others show reduced expression. These concepts form the basis of the hypothesis that "Ets conversion" occurs and is critical during tumor progression.

Transcription factor regulation is a highly complex process requiring an exact spatial and temporal coordination of multi-faceted protein complexes in order to successfully regulate the $\sim 25,000$ genes found in each human cell. Sequence specific transcription factors such as ETS factors play a crucial role in transcriptional regulation by initiating complex formation at their consensus binding motifs. Specificity is conferred through a complex series of proteinDNA and protein-protein interactions with a multitude of coactivator and/or co-repressor proteins (including chromatin remodeling and histone modifying enzymes). Correct complex formation regulates pre-initiation complex formation and in turn transcriptional activation. As mentioned above, all ETS factors recognize a common DNA binding motif (GGAA/T), and it has been shown that different ETS factors can occupy the promoters of the same genes [5, 115-117]. Two of the earlier studies found that at least three ETS factors could bind to the promoters of multiple megakaryocyte-specific genes [116, 117]. While a recent survey of the in vivo occupancy of four ETS proteins in human $\mathrm{T}$ cells found that three of these proteins often occupy the same promoter regions of housekeeping genes, this study concluded that specific binding was more correlated with more specialized genes [5]. It is clear that to fully comprehend the dynamics of ETS-mediated regulation of cancerassociated genes they must be analyzed in the context of a dynamic transcriptional regulatory network and not as individual transcription factors.

Taken together, accumulating evidence suggests that multiple ETS factors act in concert to positively and negatively regulate the pathways that control progression to metastatic cancer. This indicates a possible "Ets conversion" mechanism of gene regulation which provides the cell with 


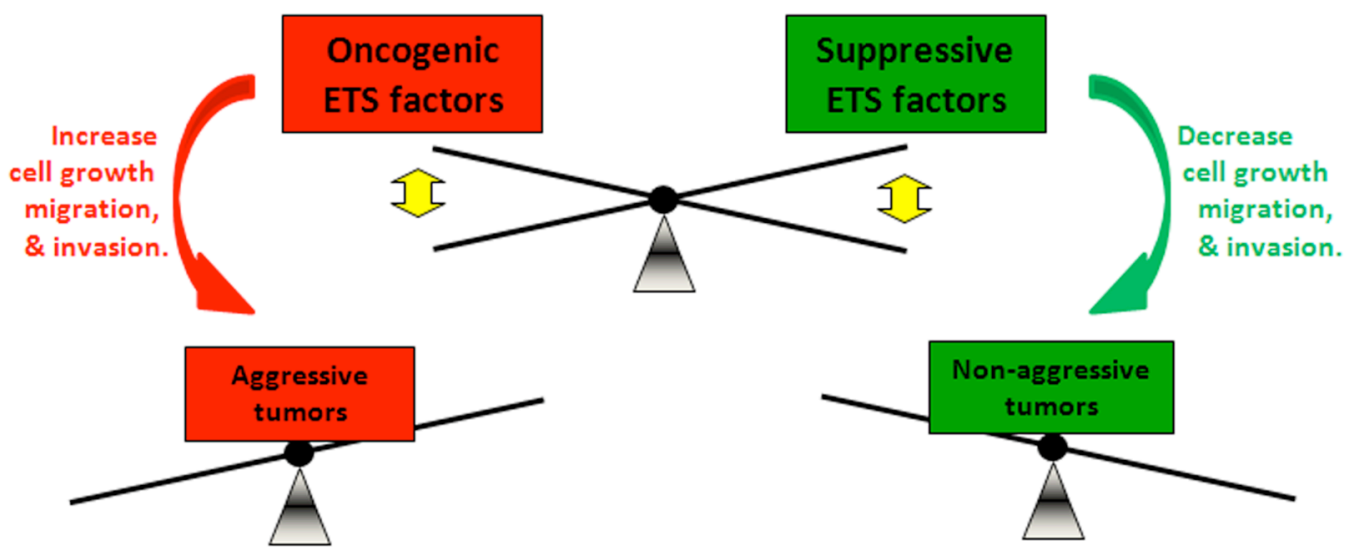

Fig. (3). A schematic model of reciprocal gene regulation by oncogenic and suppressive ETS factors during cancer progression. During normal regulation, ETS factor expression is tightly controlled to regulate many biological processes including cell proliferation, differentiation, hematopoiesis, apoptosis, metastasis, tissue remodeling, angiogenesis and transformation. In cancer, aberrant ETS factor expression results in the up-regulation of genes known to drive cancer and the down-regulation of genes known to suppress cancer.

an integrated mechanism by which to respond to a variety of intra- and extra-cellular signals efficiently [1]. In prostate cancer, increased expression of ETS1, ETS2, ERG, FLI1, and ER81 (ETV1) and the decreased expression or genomic loss of PDEF (PSE), ESE3 (EHF), and TEL (ETV6) are observed. During breast cancer progression, the expression of some ETS factors (e.g., ETS1, ETS2, PEA3, ERM, ESE1) is often increased, while the expression of other ETS factors (PDEF, ESE2, ESE3) is reduced or lost. Thus, a common feature for both prostate and breast cancer, is elevated expression of ETS1 and ETS2, and reduced expression of PDEF and ESE3. The "ETS conversion" model further hypothesizes that the change in expression pattern from what is observed in normal or benign tissues (e.g., PDEF expression) to that observed in invasive cancer (e.g., elevated ETS1) is necessary for cancer progression to proceed. Functional studies demonstrate the impact of such altered expression on the regulation of genes associated with proliferation, transformation, migration, invasion, antiapoptosis, and angiogenesis [2] and include but are not exclusive to Her2/neu, uPA, MMPs, TIMPs, MET, Bcl2, maspin, VEGFR and survivin [10, 99] (Fig. 3).

Re-examining the data provided in the survey of ETS expression in breast cancer-derived cell lines [114], ETS1 expression is higher in invasive breast cancer cell lines (BT549 and MDA-MB-231) compared to less invasive or non-invasive lines (T47D, MCF7, SkBr3 and BT474). Furthermore, PDEF transcripts show a reciprocal pattern for the same cell lines, being lower or non-detectable in the invasive lines. As noted above, while a few studies have examined the expression of multiple ETS factors in primary tumors, no study has presented relative ETS expression in a human prostate or breast cancer. These analyses are needed to determine the clinical significance of ETS conversion and whether it has predictive value. For example, do samples that have a high ETS1/PDEF ratio or an ETS1 presence/PDEF absence phenotype have a poor disease course?

Reciprocal ETS regulation of a metastasis-associated gene can be illustrated by the uPA promoter. Up-regulation of UPA has a causal role in enhancing matrix degradation, cytoskeleton re-organization, cell growth, migration and invasion (a pro-metastatic phenotype). ETS regulation of
uPA has both positive and negative effects on cancer progression depending on the specific ETS factor expressed. ETS1 is over-expressed in invasive breast and aggressive prostate cancer and associated with increased uPA expression. In non-invasive (ETS1-) breast cancer cells, reexpression of ETS1 increases uPA levels leading to a prometastatic phenotype, including increased cell growth, migration and invasion. In contrast, the expression of another ETS family member, PDEF, is present in non-invasive, but lost in invasive, breast cancer cells. In contrast to the effect of ETS1 in non-invasive cells, PDEF re-expression in invasive cells represses endogenous uPA transcription leading to an inhibition of cell growth, migration and invasion and an anti-metastatic phenotype [46, 104]. Intriguingly, although several potential EBS are found in the uPA promoter, both ETS1 and PDEF have been demonstrated to bind at the same consensus EBS in vivo.

Another example of reciprocal regulation is provided by the maspin promoter. Maspin is a type II tumor suppressor gene that has been shown to have antimetastatic properties when expressed in invasive breast cancer cells [118]. The maspin promoter has been shown to be regulated by PDEF [46, 119]. Significantly, this activation appeared to be specific for PDEF, since neither FLI1 nor ETS1 was able to activate this promoter. Indeed, ETS1 expression inhibited PDEF mediated transactivation of the maspin promoter. While both PDEF and ETS1 bind to Ets consensus sites (EBS) in the Maspin promoter, these data indicate that ETS1 can compete with PDEF for binding, and once bound, is not able to transcriptionally activate the maspin promoter. Taken together, these observations suggest that loss of PDEF protein in breast cancer cells may result in increased uPA and decreased maspin expression. These two effects may contribute to increased invasiveness and metastasis.

Taken as a whole, this evidence strongly suggests the existence of distinct ETS expression regulatory networks that act in concert to positively or negatively regulate cancer associated genes. Significantly, each ETS network would result in distinct patterns of target gene expression, the elucidation of which may identify pro-metastatic and antimetastatic signatures of gene expression that may predict the aggressive behavior of cancer cells. 


\section{FUTURE DEVELOPMENTS}

ETS factors represent one of the largest families of transcriptional regulators and have known functional roles in many biological processes. Significantly, ETS factors have oncogenic and suppressive activity and their aberrant expression is associated with many of the processes that lead to prostate cancer progression.

The well documented alterations in ETS factor expression and function during prostate and breast cancer progression result in pleiotropic effects manifested by the downstream effect on their target genes. Multiple ETS factors bind to the same regulatory sites present on target genes, suggesting redundant or competitive functions. Furthermore, additional events contribute to, or may be necessary for, target gene regulation. In order to advance our understanding of the ETS-dependent regulation of cancer progression and metastasis, future studies should be directed towards elucidation of the effects of simultaneous expression of multiple transcription factors on the transcriptome of nonmetastatic and metastatic cancer.

\section{ETS Mediated Anti-and Pro-Metastatic Signatures}

Gene expression signatures consist of sets of gene profiles that are known to be predictive of a disease state and/or patient response to treatment. The combined statistical analysis of multiple gene sets obtained from independent gene microarray studies has resulted in an increased number of putative and validated "metastatic signatures" that predict the outcome of disease in cancer. In addition, comparison of gene expression profiles from primary and metastatic tumors in multiple cancer types reveals highly specific signatures that allow discrimination between primary and metastatic tumors. Similarly, by elucidating the expression networks conferred by ETS family members that elicit a pro-metastatic response (ETS1, etc.) and an anti-metastatic response (PDEF, etc.), improved pro- and anti-metastatic signatures may be isolated that predict the aggressive behavior of cancer cells. As such, these new insights may provide a novel view of the ETS gene family as well as a focal point for studying the complex biological control involved in tumor progression.

In addition, a better definition of genes whose expression is functionally important for metastatic progression will highlight new therapeutic targets and diagnostic factors. While targeting transcription factors themselves directly (e.g. Androgen Receptor), indirectly targeting of transcription for therapeutic gain has been met with some success [4]. Therefore, better understanding the mechanisms that regulate ETS factor activity during both normal and aberrant transcription provides a novel means to identify processes that may be targeted in order to re-establish the normal ETSregulatory networks that are perturbed in cancer [2]. Specific examples of therapeutic technologies that may be used to target ETS factors and their co-factor and downstream target genes in prostate cancer have recently been reviewed [4].

\section{Whole Genome Location Analysis}

As technologies have advanced it has become possible for researchers to identify the true regulatory targets of transcription factors. Chromatin immunoprecipitation (ChIP) is an established method for the analysis of protein-DNA (gene regulatory elements) interactions in vivo. Sequential ChIP is an extension of the ChIP protocol, in which the immunoprecipitated chromatin is subjected to sequential immunoprecipitations with antibodies of different specificity. This provides a method of examining cooccupancy of defined promoters by multiple regulatory proteins. Furthermore, sequential ChIP provides an experimental approach to simultaneously evaluate promoter occupancy and transcriptional status (e.g., histone H3 acetylation, phosphorylated RNAPII-CTD [116]). However, ChiP and sequential ChIP methods are restricted to the analysis of small promoter regions, the boundaries defined by the sequences of the primers designed for the PCR amplification step.

To determine the more global location of in vivo promoter binding sites of a specific protein, ChIP protocols have been combined with whole genome analysis methods to produce "ChIP-on-chip" microarrays. ChIP products are hybridized to arrays consisting of promoter regions, $\mathrm{CpG}$ islands or whole genomes and are used to identify not only DNA binding sites, but also transcriptional co-factors and chromatin structure definition. ChIP sequencing (ChIP-seq) is the next generation protocol for defining Protein-DNA transcriptomes [120-122]. It combines ChIP with new high throughput sequencing platforms, such as Genome Analyzer (Solexa/Illumina). This increases cost effectiveness, reduces hands on processing times and requires fewer replicates and starting material to reduced bias, and generates significantly more informative data [123].

In the context of an ETS transcription network, ChIP-seq analysis can potentially identify the full transcriptome for each individual ETS family member in any given scenario. For example, by defining the metastasis suppressing PDEF transcriptome in non-invasive cancer cells and metastasis activating ETS1 transcriptome in invasive cancer cells, specific ETS mediated transcriptional networks may be identified which confer an anti- or pro-metastatic phenotype. Furthermore, by comparing ChIP-seq data with microarray profiles obtained following ETS expression, direct and indirect targets for each ETS factor can be ascertained. It will also allow the identification of genes directly regulated by more than one specific ETS factor, such as that observed for UPA, which is directly regulated by either ETS1 or PDEF, depending on cell context. In addition, the genes that are identified on expression microarrays and are not identified as direct targets on ChIP-on-chip microarrays or Chip-seq will define indirect or downstream targets, providing further insight into the complex nature of ETS transcriptional regulatory networks. The identification of genome wide binding sites may also indicate the functions of various transcriptional regulators and help identify their target genes during development and disease progression.

In summary, while expression and promoter arrays will allow identification of new cancer associated target genes that are regulated by ETS transcription factors, concomitant molecular studies will increase our understanding of the mechanisms by which ETS transcription factors act as oncogenes and tumor suppressor genes. The holy grail of any therapeutic cancer regime is the re-activation of tumor suppressor function and/or the inhibition of oncogene 
activation. Direct or indirect therapeutic intervention of ETS factor function or regulation offers intriguing possibilities in order to achieve this.

\section{ACKNOWLEDGEMENTS}

We apologize to those researchers whose work could not be cited because of space limitations or was only cited indirectly by referring to reviews or more recent publications. This work was supported in part by a grant from the National Cancer Institute (P01 CA78582).

\section{REFERENCES}

[1] Hsu T, Trojanowska M, Watson DK. ETS proteins in biological control and cancer. J Cell Biochem 2004; 91: 896-903.

[2] Seth A, Watson DK. ETS transcription factors and their emerging roles in human cancer. Eur J Cancer 2005; 41: 2462-78.

[3] Gutierrez-Hartmann A, Duval DL, Bradford AP. ETS transcription factors in endocrine systems. Trends Endocrinol Metab 2007; 18: $150-8$.

[4] Turner DP, Watson DK. ETS transcription factors: oncogenes and tumor suppressor genes as therapeutic targets for prostate cancer. Expert Rev Anticancer Ther 2008; 8: 33-42.

[5] Hollenhorst PC, Shah AA, Hopkins C, Graves BJ. Genome-wide analyses reveal properties of redundant and specific promoter occupancy within the ETS gene family. Genes Dev 2007; 21: 188294.

[6] Feldman RJ, Sementchenko VI, Watson DK. The epithelialspecific Ets factors occupy a unique position in defining epithelial proliferation, differentiation and carcinogenesis. Anticancer Res 2003; 23: 2125-31.

[7] Tootle TL, Rebay I. Post-translational modifications influence transcription factor activity: a view from the ETS superfamily. Bioessays 2005; 27: 285-98.

[8] Li R, Pei H, Watson DK. Regulation of ETS function by protein protein interactions. Oncogene 2000; 19: 6514-23.

[9] Verger A, Duterque-Coquillaud M. When ETS transcription factors meet their partners. Bioessays 2002; 24: 362-70.

[10] Sementchenko VI, Watson DK. ETS target genes: past, present and future. Oncogene 2000; 19: 6533-48.

[11] Gavrilov D, Kenzior O, Evans M, Calaluce R, Folk WR. Expression of urokinase plasminogen activator and receptor in conjunction with the ets family and AP-1 complex transcription factors in high grade prostate cancers. Eur J Cancer 2001; 37: 1033-40.

[12] Alipov G, Nakayama T, Ito M, et al. Overexpression of ETS-1 proto-oncogene in latent and clinical prostatic carcinomas. Histopathology 2005; 46: 202-8.

[13] Massie CE, Adryan B, Barbosa-Morais NL, et al. New androgen receptor genomic targets show an interaction with the ETS1 transcription factor. EMBO Rep 2007; 8: 871-8.

[14] Liu AY, Corey E, Vessella RL, et al. Identification of differentially expressed prostate genes: increased expression of transcription factor ETS-2 in prostate cancer. Prostate 1997; 30: 145-53.

[15] Ernst T, Hergenhahn M, Kenzelmann M, et al. Decrease and gain of gene expression are equally discriminatory markers for prostate carcinoma: a gene expression analysis on total and microdissected prostate tissue. Am J Pathol 2002; 160: 2169-80.

[16] Sementchenko VI, Schweinfest CW, Papas TS, Watson DK. ETS2 function is required to maintain the transformed state of human prostate cancer cells. Oncogene 1998; 17: 2883-8.

[17] Carbone GM, Napoli S, Valentini A, et al. Triplex DNA-mediated downregulation of ETS2 expression results in growth inhibition and apoptosis in human prostate cancer cells. Nucleic Acids Res 2004; 32: 4358-67.

[18] Hever A, Oshima RG, Hauser CA. ETS2 is not required for Ras or $\mathrm{Neu} / \mathrm{ErbB}-2$ mediated cellular transformation in vitro. Exp Cell Res 2003; 290: 132-43.

[19] Petrovics G, Liu A, Shaheduzzaman S, et al. Frequent overexpression of ETS-related gene-1 (ERG1) in prostate cancer transcriptome. Oncogene 2005; 24: 3847-52.
[20] Tomlins SA, Rhodes DR, Perner S, et al. Recurrent fusion of TMPRSS2 and ETS transcription factor genes in prostate cancer. Science 2005; 310: 644-8.

[21] Soller MJ, Isaksson M, Elfving P, et al. Confirmation of the high frequency of the TMPRSS2/ERG fusion gene in prostate cancer. Genes Chromosomes Cancer 2006; 45: 717-9.

[22] Kumar-Sinha C, Tomlins SA, Chinnaiyan AM. Recurrent gene fusions in prostate cancer. Nat Rev Cancer 2008; 8: 497-511.

[23] Shah RB, Chinnaiyan AM. The discovery of common recurrent transmembrane protease serine 2 (TMPRSS2)-erythroblastosis virus E26 transforming sequence (ETS) gene fusions in prostate cancer: significance and clinical implications. Adv Anat Pathol 2009; 16: 145-53.

[24] Perner S, Demichelis F, Beroukhim R, et al. TMPRSS2:ERG fusion-associated deletions provide insight into the heterogeneity of prostate cancer. Cancer Res 2006; 66: 8337-41.

[25] Clark J, Merson S, Jhavar S, et al. Diversity of TMPRSS2-ERG fusion transcripts in the human prostate. Oncogene 2007; 26: 266773.

[26] Hu Y, Dobi A, Sreenath T, et al. Delineation of TMPRSS2-ERG splice variants in prostate cancer. Clin Cancer Res 2008; 14: 471925.

[27] Cerveira N, Ribeiro FR, Peixoto A, et al. TMPRSS2-ERG gene fusion causing ERG overexpression precedes chromosome copy number changes in prostate carcinomas and paired HGPIN lesions. Neoplasia 2006; 8: 826-32.

[28] Mosquera JM, Perner S, Demichelis F, et al. Morphological features of TMPRSS2-ERG gene fusion prostate cancer. J Pathol 2007; 212: 91-101.

[29] Attard G, Clark J, Ambroisine L, et al. Duplication of the fusion of TMPRSS2 to ERG sequences identifies fatal human prostate cancer. Oncogene 2008; 27(3): 253-63.

[30] Demichelis F, Fall K, Perner S, et al. TMPRSS2:ERG gene fusion associated with lethal prostate cancer in a watchful waiting cohort. Oncogene 2007; 26: 4596-9.

[31] Setlur SR, Mertz KD, Hoshida Y, et al. Estrogen-dependent signaling in a molecularly distinct subclass of aggressive prostate cancer. J Natl Cancer Inst 2008; 100: 815-25.

[32] Tomlins SA, Mehra R, Rhodes DR, et al. TMPRSS2:ETV4 gene fusions define a third molecular subtype of prostate cancer. Cancer Res 2006; 66: 3396-400.

[33] Tomlins SA, Laxman B, Dhanasekaran SM, et al. Distinct classes of chromosomal rearrangements create oncogenic ETS gene fusions in prostate cancer. Nature 2007; 448: 595-9.

[34] Helgeson BE, Tomlins SA, Shah N, et al. Characterization of TMPRSS2:ETV5 and SLC45A3:ETV5 gene fusions in prostate cancer. Cancer Res 2008; 68: 73-80.

[35] Attard G, Jameson C, Moreira J, et al. Hormone-sensitive prostate cancer: a case of ETS gene fusion heterogeneity. J Clin Pathol 2009; 62: 373-6.

[36] Clark JP, Cooper CS. ETS gene fusions in prostate cancer. Nat Rev Urol 2009; 6: 429-39.

[37] Rickman DS, Pflueger D, Moss B, et al. SLC45A3-ELK4 is a novel and frequent erythroblast transformation-specific fusion transcript in prostate cancer. Cancer Res 2009; 69: 2734-8.

[38] Sun C, Dobi A, Mohamed A, et al. TMPRSS2-ERG fusion, a common genomic alteration in prostate cancer activates C-MYC and abrogates prostate epithelial differentiation. Oncogene 2008; 27: 5348-53.

[39] Tomlins SA, Laxman B, Varambally S, et al. Role of the TMPRSS2-ERG gene fusion in prostate cancer. Neoplasia 2008; 10: $177-88$.

[40] Carver BS, Tran J, Gopalan A, et al. Aberrant ERG expression cooperates with loss of PTEN to promote cancer progression in the prostate. Nat Genet 2009; 41: 619-24.

[41] Klezovitch O, Risk M, Coleman I, et al. A causal role for ERG in neoplastic transformation of prostate epithelium. Proc Natl Acad Sci USA 2008; 105: 2105-10.

[42] Cai C, Hsieh CL, Omwancha J, et al. ETV1 is a novel androgen receptor-regulated gene that mediates prostate cancer cell invasion. Mol Endocrinol 2007; 21: 1835-46.

[43] Demichelis F, Setlur SR, Beroukhim R, et al. Distinct genomic aberrations associated with ERG rearranged prostate cancer. Genes Chromosomes Cancer 2009; 48: 366-80. 
[44] Rostad K, Mannelqvist M, Halvorsen OJ, et al. ERG upregulation and related ETS transcription factors in prostate cancer. Int J Oncol 2007; 30: 19-32.

[45] Nozawa M, Yomogida K, Kanno N, et al. Prostate-specific transcription factor hPSE is translated only in normal prostate epithelial cells. Cancer Res 2000; 60: 1348-52.

[46] Feldman RJ, Sementchenko VI, Gayed M, Fraig MM, Watson DK. Pdef expression in human breast cancer is correlated with invasive potential and altered gene expression. Cancer Res 2003; 63: 462631

[47] Ghadersohi A, Odunsi K, Zhang S, et al. Prostate-derived ETS transcription factor as a favorable prognostic marker in ovarian cancer patients. Int J Cancer 2008; 123: 1376-84.

[48] Tsujimoto $\mathrm{Y}$, Nonomura $\mathrm{N}$, Takayama $\mathrm{H}$, et al. Utility of immunohistochemical detection of prostate-specific ETS for the diagnosis of benign and malignant prostatic epithelial lesions. Int $\mathbf{J}$ Urol 2002; 9: 167-72.

[49] Sood AK, Saxena R, Groth J, et al. Expression characteristics of prostate-derived ETS factor support a role in breast and prostate cancer progression. Hum Pathol 2007; 38: 1628-38.

[50] Fowler M, Borazanci E, McGhee L, et al. RUNX1 (AML-1) and RUNX2 (AML-3) cooperate with prostate-derived ETS factor to activate transcription from the PSA upstream regulatory region. J Cell Biochem 2006; 97: 1-17.

[51] Oettgen P, Finger E, Sun Z, et al. PDEF, a novel prostate epithelium-specific ETS transcription factor, interacts with the androgen receptor and activates prostate-specific antigen gene expression. J Biol Chem 2000; 275: 1216-25.

[52] Chen H, Nandi AK, Li X, Bieberich CJ. NKX-3.1 interacts with prostate-derived ETS factor and regulates the activity of the PSA promoter. Cancer Res 2002; 62: 338-40.

[53] Gu X, Zerbini LF, Otu HH, et al. Reduced PDEF expression increases invasion and expression of mesenchymal genes in prostate cancer cells. Cancer Res 2007; 67: 4219-26.

[54] Tugores A, Le J, Sorokina I, et al. The epithelium-specific ETS protein EHF/ESE-3 is a context-dependent transcriptional repressor downstream of MAPK signaling cascades. J Biol Chem 2001; 276: 20397-406.

[55] Cangemi R, Mensah A, Albertini V, et al. Reduced expression and tumor suppressor function of the ETS transcription factor ESE-3 in prostate cancer. Oncogene 2008; 27: 2877-85.

[56] Park C, Lee I, Kang WK. Influence of small interfering RNA corresponding to ets homologous factor on senescence-associated modulation of prostate carcinogenesis. Mol Cancer Ther 2006; 5: 3191-6.

[57] Kibel AS, Schutte M, Kern SE, Isaacs WB, Bova GS. Identification of $12 p$ as a region of frequent deletion in advanced prostate cancer. Cancer Res 1998; 58: 5652-5.

[58] Kibel AS, Freije D, Isaacs WB, Bova GS. Deletion mapping at 12 p12-13 in metastatic prostate cancer. Genes Chromosomes Cancer 1999; 25: 270-6.

[59] Kibel AS, Faith DA, Bova GS, Isaacs WB. Mutational analysis of ETV6 in prostate carcinoma. Prostate 2002; 52: 305-10

[60] Carver BS, Tran J, Chen Z, et al. ETS rearrangements and prostate cancer initiation. Nature 2009; 457: E1; discussion E2-3.

[61] King JC, Xu J, Wongvipat J, et al. Cooperativity of TMPRSS2ERG with PI3-kinase pathway activation in prostate oncogenesis. Nat Genet 2009; 41: 524-6.

[62] Behrens P, Rothe M, Wellmann A, Krischler J, Wernert N. The ETS-1 transcription factor is up-regulated together with MMP 1 and MMP 9 in the stroma of pre-invasive breast cancer. J Pathol 2001; 194: 43-50

[63] Span PN, Manders P, Heuvel JJ, et al. Expression of the transcription factor ETS-1 is an independent prognostic marker for relapse-free survival in breast cancer. Oncogene 2002; 21: 8506-9.

[64] Buggy Y, Maguire TM, McGreal G, et al. Overexpression of the ETS-1 transcription factor in human breast cancer. Br J Cancer 2004; 91: 1308-15.

[65] Katayama S, Nakayama T, Ito M, Naito S, Sekine I. Expression of the ETS-1 proto-oncogene in human breast carcinoma: differential expression with histological grading and growth pattern. Histol Histopathol 2005; 20: 119-26

[66] Myers E, Hill AD, Kelly G, et al. Associations and interactions between ETS-1 and ETS-2 and coregulatory proteins, SRC-1, AIB1, and NCoR in breast cancer. Clin Cancer Res 2005; 11: 2111-22.
[67] Gilles C, Polette M, Birembaut P, Brunner N, Thompson EW. Expression of c-ETS-1 mRNA is associated with an invasive, EMT-derived phenotype in breast carcinoma cell lines. Clin Exp Metastasis 1997; 15: 519-26.

[68] Park YH, Jung HH, Ahn JS, Im YH. ETS-1 upregulates HER2induced MMP-1 expression in breast cancer cells. Biochem Biophys Res Commun 2008; 377: 389-94.

[69] Maroni P, Bendinelli P, Matteucci E, Desiderio MA. HGF induces CXCR4 and CXCL12-mediated tumor invasion through ETS1 and NF-kappaB. Carcinogenesis 2007; 28: 267-79.

[70] Furlan A, Vercamer C, Desbiens X, Pourtier A. ETS-1 triggers and orchestrates the malignant phenotype of mammary cancer cells within their matrix environment. J Cell Physiol 2008; 215: 782-93.

[71] Pei H, Yordy JS, Leng Q, et al. EAPII interacts with ETS1 and modulates its transcriptional function. Oncogene 2003; 22: 2699709 .

[72] Yordy JS, Li R, Sementchenko VI, et al. SP100 expression modulates ETS1 transcriptional activity and inhibits cell invasion. Oncogene 2004; 23: 6654-65.

[73] Buggy Y, Maguire TM, McDermott E, et al. ETS2 transcription factor in normal and neoplastic human breast tissue. Eur J Cancer 2006; 42: 485-91.

[74] Svensson S, Jirstrom K, Ryden L, et al. ERK phosphorylation is linked to VEGFR2 expression and ETS-2 phosphorylation in breast cancer and is associated with tamoxifen treatment resistance and small tumours with good prognosis. Oncogene 2005; 24: 4370-9.

[75] Sapi E, Flick MB, Rodov S, Kacinski BM. ETS-2 transdominant mutant abolishes anchorage-independent growth and macrophage colony-stimulating factor-stimulated invasion by BT20 breast carcinoma cells. Cancer Res 1998; 58: 1027-33

[76] Xu D, Dwyer J, Li H, Duan W, Liu JP. ETS2 maintains hTERT gene expression and breast cancer cell proliferation by interacting with c-Myc. J Biol Chem 2008; 283: 23567-80.

[77] Baker KM, Wei G, Schaffner AE, Ostrowski MC. ETS-2 and components of mammalian SWI/SNF form a repressor complex that negatively regulates the BRCA1 promoter. J Biol Chem 2003; 278: 17876-84

[78] Benz CC, O'Hagan RC, Richter B, et al. HER2/Neu and the ETS transcription activator PEA3 are coordinately upregulated in human breast cancer. Oncogene 1997; 15: 1513-25.

[79] Davidson B, Goldberg I, Tell L, et al. The clinical role of the PEA3 transcription factor in ovarian and breast carcinoma in effusions. Clin Exp Metastasis 2004; 21: 191-9.

[80] Davidson B, Konstantinovsky S, Nielsen S, et al. Altered expression of metastasis-associated and regulatory molecules in effusions from breast cancer patients: a novel model for tumor progression. Clin Cancer Res 2004; 10: 7335-46.

[81] Bieche I, Tozlu S, Girault I, et al. Expression of $\mathrm{PEA} 3 / \mathrm{E} 1 \mathrm{AF} / \mathrm{ETV} 4$, an ETS-related transcription factor, in breast tumors: positive links to MMP2, NRG1 and CGB expression. Carcinogenesis 2004; 25: 405-11.

[82] Myers E, Hill AD, Kelly G, et al. A positive role for PEA3 in HER2-mediated breast tumour progression. Br J Cancer 2006; 95: 1404-9.

[83] Xia WY, Lien HC, Wang SC, et al. Expression of PEA3 and lack of correlation between PEA3 and HER-2/neu expression in breast cancer. Breast Cancer Res Treat 2006; 98: 295-301.

[84] Bosc DG, Goueli BS, Janknecht R. HER2/Neu-mediated activation of the ETS transcription factor ER81 and its target gene MMP-1. Oncogene 2001; 20: 6215-24.

[85] Scott GK, Daniel JC, Xiong X, et al. Binding of an ETS-related protein within the DNase I hypersensitive site of the HER2/neu promoter in human breast cancer cells. J Biol Chem 1994; 269 19848-58.

[86] Yang JW, Kim MR, Kim HG, et al. Differential regulation of ErbB2 expression by cAMP-dependent protein kinase in tamoxifen-resistant breast cancer cells. Arch Pharm Res 2008; 31: 350-6.

[87] Kaya M, Yoshida K, Higashino F, et al. A single ETS-related transcription factor, E1AF, confers invasive phenotype on human cancer cells. Oncogene 1996; 12: 221-7.

[88] Jiang J, Wei Y, Liu D, et al. E1AF promotes breast cancer cell cycle progression via upregulation of Cyclin D3 transcription. Biochem Biophys Res Commun 2007; 358: 53-8. 
[89] Chotteau-Lelievre A, Revillion F, Lhotellier V, et al. Prognostic value of ERM gene expression in human primary breast cancers. Clin Cancer Res 2004; 10: 7297-303.

[90] Chang CH, Scott GK, Kuo WL, et al. ESX: a structurally unique ETS overexpressed early during human breast tumorigenesis. Oncogene 1997; 14: 1617-22.

[91] Eckel KL, Tentler JJ, Cappetta GJ, Diamond SE, GutierrezHartmann A. The epithelial-specific ETS transcription factor ESX/ESE-1/Elf-3 modulates breast cancer-associated gene expression. DNA Cell Biol 2003; 22: 79-94.

[92] Schedin PJ, Eckel-Mahan KL, McDaniel SM, et al. ESX induces transformation and functional epithelial to mesenchymal transition in MCF-12A mammary epithelial cells. Oncogene 2004; 23: 176679.

[93] Teixeira MR. Recurrent fusion oncogenes in carcinomas. Crit Rev Oncog 2006; 12: 257-71.

[94] Tognon C, Knezevich SR, Huntsman D, et al. Expression of the ETV6-NTRK3 gene fusion as a primary event in human secretory breast carcinoma. Cancer Cell 2002; 2: 367-76.

[95] Letessier A, Ginestier C, Charafe-Jauffret E, et al. ETV6 gene rearrangements in invasive breast carcinoma. Genes Chromosomes Cancer 2005; 44: 103-8.

[96] Ghadersohi A, Odunsi K, Lele S, et al. Prostate derived ETS transcription factor shows better tumor-association than other cancer-associated molecules. Oncol Rep 2004; 11: 453-8.

[97] Gunawardane RN, Sgroi DC, Wrobel CN, et al. Novel role for PDEF in epithelial cell migration and invasion. Cancer Res 2005; 65: 11572-80.

[98] Turcotte S, Forget MA, Beauseigle D, Nassif E, Lapointe R. Prostate-derived ETS transcription factor overexpression is associated with nodal metastasis and hormone receptor positivity in invasive breast cancer. Neoplasia 2007; 9: 788-96.

[99] Ghadersohi A, Pan D, Fayazi Z, et al. Prostate-derived ETS transcription factor (PDEF) downregulates survivin expression and inhibits breast cancer cell growth in vitro and xenograft tumor formation in vivo. Breast Cancer Res Treat 2007; 102: 19-30.

[100] Perou CM, Sorlie T, Eisen MB, et al. Molecular portraits of human breast tumours. Nature 2000; 406: 747-52.

[101] Neve RM, Chin K, Fridlyand J, et al. A collection of breast cancer cell lines for the study of functionally distinct cancer subtypes. Cancer Cell 2006; 10: 515-27.

[102] Doane AS, Danso M, Lal P, et al. An estrogen receptor-negative breast cancer subset characterized by a hormonally regulated transcriptional program and response to androgen. Oncogene 2006; 25: 3994-4008.

[103] Sood AK, Wang J, Mhawech-Fauceglia P, et al. Sam-pointed domain containing ETS transcription factor in luminal breast cancer pathogenesis. Cancer Epidemiol Biomarkers Prev 2009; 18: 1899-903.

[104] Turner DP, Moussa O, Sauane M, Fisher PB, Watson DK. Prostatederived ETS factor is a mediator of metastatic potential through the inhibition of migration and invasion in breast cancer. Cancer Res 2007; 67: 1618-25.

[105] Turner DP, Findlay VJ, Kirven AD, Moussa O, Watson DK. Global gene expression analysis identifies PDEF transcriptional networks regulating cell migration during cancer progression. Mol Biol Cell 2008; 19: 3745-57.

[106] Kleinbaum LA, Duggan C, Ferreira E, et al. Human chromosomal localization, tissue/tumor expression, and regulatory function of the ets family gene EHF. Biochem Biophys Res Commun 1999; 264: 119-26.

[107] Shepherd TG, Kockeritz L, Szrajber MR, Muller WJ, Hassell JA. The pea3 subfamily ETS genes are required for HER2/Neumediated mammary oncogenesis. Curr Biol 2001; 11: 1739-48.

[108] Neznanov N, Man AK, Yamamoto H, et al. A single targeted Ets2 allele restricts development of mammary tumors in transgenic mice. Cancer Res 1999; 59: 4242-6.

[109] Tynan JA, Wen F, Muller WJ, Oshima RG. ETS2-dependent microenvironmental support of mouse mammary tumors. Oncogene 2005; 24: 6870-6.

[110] Li Z, Tognon CE, Godinho FJ, et al. ETV6-NTRK3 fusion oncogene initiates breast cancer from committed mammary progenitors via activation of AP1 complex. Cancer Cell 2007; 12: 542-58.

[111] Findlay VJ, Turner DP, Moussa O, Watson DK. MicroRNAmediated inhibition of prostate-derived ETS factor messenger RNA translation affects prostate-derived ETS factor regulatory networks in human breast cancer. Cancer Res 2008; 68: 8499-506.

[112] Iljin K, Wolf M, Edgren H, et al. TMPRSS2 fusions with oncogenic ETS factors in prostate cancer involve unbalanced genomic rearrangements and are associated with $\mathrm{HDAC1}$ and epigenetic reprogramming. Cancer Res 2006; 66: 10242-6.

[113] Galang CK, Muller WJ, Foos G, Oshima RG, Hauser CA. Changes in the expression of many ETS family transcription factors and of potential target genes in normal mammary tissue and tumors. J Biol Chem 2004; 279: 11281-92.

[114] He J, Pan Y, Hu J, et al. Profile of ETS gene expression in human breast carcinoma. Cancer Biol Ther 2007; 6: 76-82.

[115] Hollenhorst PC, Jones DA, Graves BJ. Expression profiles frame the promoter specificity dilemma of the ETS family of transcription factors. Nucleic Acids Res 2004; 32: 5693-702.

[116] Jackers P, Szalai G, Moussa O, Watson DK. ETS-dependent regulation of target gene expression during megakaryopoiesis. J Biol Chem 2004; 279: 52183-90.

[117] Pang L, Xue HH, Szalai G, et al. Maturation stage-specific regulation of megakaryopoiesis by pointed-domain ETS proteins. Blood 2006; 108: 2198-206.

[118] Zou Z, Anisowicz A, Hendrix MJ, et al. Maspin, a serpin with tumor-suppressing activity in human mammary epithelial cells. Science 1994; 263: 526-9.

[119] Yamada N, Tamai Y, Miyamoto H, Nozaki M. Cloning and expression of the mouse Pse gene encoding a novel ETS family member. Gene 2000; 241: 267-74.

[120] Farnham PJ. Insights from genomic profiling of transcription factors. Nat Rev Genet 2009; 10: 605-16.

[121] Schmidt D, Wilson MD, Spyrou C, et al. ChIP-seq: using highthroughput sequencing to discover protein-DNA interactions. Methods 2009; 48: 240-8.

[122] Visel A, Blow MJ, Li Z, et al. ChIP-seq accurately predicts tissuespecific activity of enhancers. Nature 2009; 457: 854-8.

[123] Mardis ER. ChIP-seq: welcome to the new frontier. Nat Methods 2007; 4: 613-4.

[124] Lapinskas EJ, Palmer J, Ricardo S, et al. A major site of expression of the ets transcription factor Elf5 is epithelia of exocrine glands. Histochem Cell Biol 2004; 122: 521-6.

[125] Ghadersohi A, Sood AK. Prostate epithelium-derived ETS transcription factor mRNA is overexpressed in human breast tumors and is a candidate breast tumor marker and a breast tumor antigen. Clin Cancer Res 2001; 7: 2731-8. 